Thermal Science and Engineering (2018) Volume 1 doi: $10.24294 /$ tse.v1i4.874

\title{
Experimental and Simulative Investigation of the Oil Distribution during A deep-hole Drilling Process and Comparing of the RANS $k$ - $\omega$-SST and RANS Hybrid SAS-SST Turbulence Model
}

\section{Ekrem Oezkaya*, Dirk Biermann}

Institute of Machining Technology, 44227 Dortmund, Germany

${ }^{*}$ Corresponding Author: E-mail address: oezkaya@isf.de, (0000-0002-4309-2238)

\begin{abstract}
Helical deep hole drilling is a process frequently used in industrial applications to produce bores with a large length to diameter ratio. For better cooling and lubrication, the deep drilling oil is fed directly into the bore hole via two internal cooling channels. Due to the inaccessibility of the cutting area, experimental investigations that provide information on the actual machining and cooling behavior are difficult to carry out. In this paper, the distribution of the deep drilling oil is investigated both experimentally and simulatively and the results are evaluated. For the Computational Fluid Dynamics (CFD) simulation, two different turbulence models, i.e. the RANS $k-\omega$-SST and hybrid SAS-SST model, are used and compared. Thereby, the actual used deep drilling oil is modelled instead of using fluid dynamic parameters of water, as is often the case. With the hybrid SAS-SST model, the flow could be analyzed much better than with the RANS $k$ - $\omega$-SST model and thus the processes that take place during helical deep drilling could be simulated with realistic details. Both the experimental and the simulative results show that the deep drilling oil movement is almost exclusively generated by the tool rotation. At the tool's cutting edges and in the flute, the flow velocity drops to zero for the most part, so that no efficient cooling and lubrication could take place there. In addition, cavitation bubbles form and implode, concluding in the assumption that the process heat is not adequately dissipated and the removal of chips is adversely affected, which in turn can affect the service life of the tool and the bore quality. The carried out investigations show that the application of CFD simulation is an important research instrument in machining technology and that there is still great potential in the area of tool and process optimization.
\end{abstract}

Keywords: Deep-hole Drilling; Twist Drill, CFD Simulation; RANS $k$ - $\omega$-SST Turbulence Model; RANS Hybrid SAS-SST Turbulence Model

\section{Introduction}

The deep drilling process is used for the production of bores with a large length to diameter ratio for various technological applications, such as cooling channel bores in turbine blades in aerospace engineering, injection technology in automotive engineering, for bone nails and surgical needles in medical technology, in process and in measurement technology (Figure 1). Depending on the application, processes such as the single-lip or BTA deep hole drilling are used. In comparison, the use of twisted drills can achieve much higher productivity and flexibility ${ }^{[1,2]}$. However, there is currently a lack of sound knowledge about the process behavior of complex machining operations, so that appropriate research must be carried out in order to improve process reliability and the resulting workpiece quality ${ }^{[3]}$. This applies in particular to drilling tools with very small diameters, which includes drills up to $\mathrm{d}=5 \mathrm{~mm}$, since the specific cutting edge load increases with decreasing tool diameter ${ }^{[4]}$. With increasing drilling depth, unfavorable chip shapes and correspondingly unfavorable chip removal can occur, resulting from the relatively small chip space cross-section ${ }^{[4]}$. Adequate cooling, which reduces mechanical and thermal loads and supports chip removal, is more difficult because the cutting zone is located inside of the workpiece. For this reason, the metal work fluid (MWF) is guided from the rear end of the tool shank to the tool tip through internal coolant channels ${ }^{[5]}$. However, as shown in other

Copyright (C) 2018 Ekrem Oezkaya et al.

doi: $10.24294 /$ tse.v1i4.874

EnPress Publisher LLC.This work is licensed under the Creative Commons Attribution-NonCommercial 4.0 International License (CC BY-NC 4.0).

http://creativecommons.org/licenses/ by/4.0/ 
investigations carried out by using CFD simulation, it can be seen that a sufficient supply of cooling lubricant is not guaranteed in many drilling processes, despite the internal cooling application, leading to subsequent modifications of the tool geometry to improve the cooling quality. In helical drilling, for example, the geometrical properties of the tool's free surface influence the coolant flow and thus also the cooling efficiency ${ }^{[5]}$. Another examination of helical twist drilling showed that a modification of the free surface favored the coolant distribution, so that the service life of the tool could be increased by $50 \%{ }^{[6]}$. Contrary to the usual assumptions that a better coolant supply is achieved by increasing the internal cooling channel diameters, recent studies have shown that this is not the case, since only an increased coolant pressure could contribute to a better cooling efficiency ${ }^{[7]}$. In tapping, a significantly better coolant distribution was achieved by changing the arrangement of the internal cooling channels, resulting in an improvement of tool performance by almost $40 \%{ }^{[8]}$. With a combined simulation approach, it could also be shown that a sufficient coolant supply is not guaranteed for single-lip deep drilling with very small diameters ${ }^{[9]}$. All these results show that there is still a lot of research and development work to be done in the field of coolant supply and that the use of CFD is a promising approach for detailed investigations in order to exploit the optimization potential of cutting tools ${ }^{[10]}$.

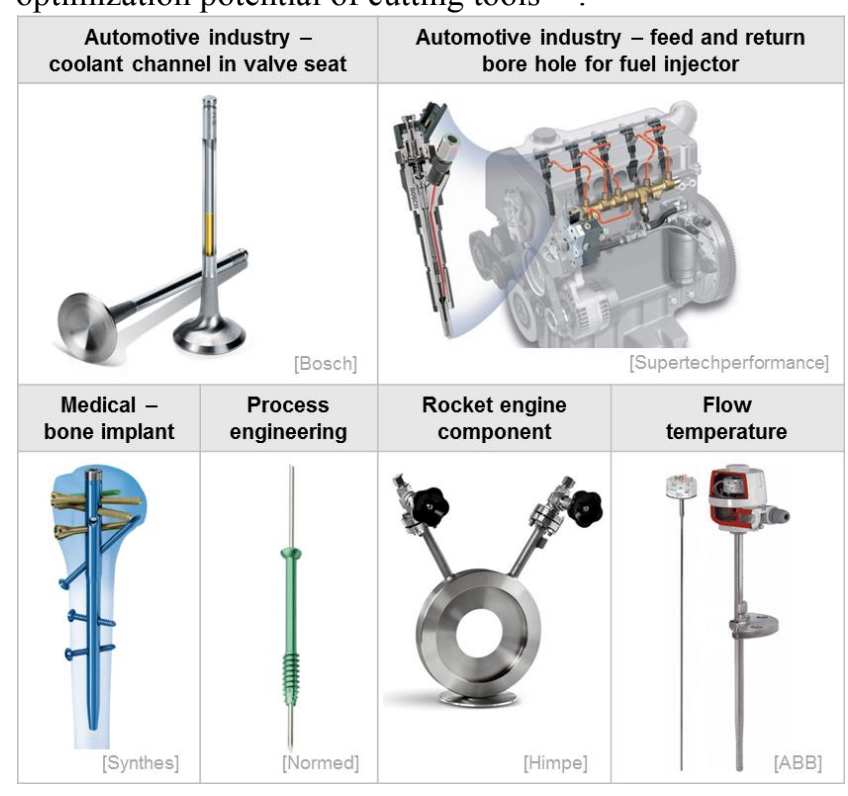

Figure 1; Application areas of deep hole drilling ${ }^{[1-16]}$.

\section{Experimental setup and results}

2.1 Experiment setup
The utilized high-speed chip formation analysis is a newly developed method for a detailed chip formation analysis, which uses high-speed microscopy ${ }^{[17]}$. In addition to the chip formation analysis, it is also possible to investigate the flow profile of the cooling lubricant, in this case Motorex deep drilling oil with a viscosity of $\mathrm{v}=10.9 \mathrm{~mm} 2 / \mathrm{sec}\left(40^{\circ} \mathrm{C}\right)$. To analyze the flow path, workpieces made of X2CrNiMo17-12-2 (AISI 316L) were placed in transparent acrylic glass samples to ensure a clear view of the chip formation and the flow path of the cooling lubricant. The experimental helical deep drilling investigations were carried out on a deep drilling machine type ML 200 from TBT. The process forces were measured with a 4-component dynamometer type 9272 and a charge amplifier type 5070 from Kistler and the data was processed using the software DIAdem so that the respective torques values could be evaluated. The experimental test were recorded with a high-speed camera focused on the stationary workpiece test sample holder. Figure 2 shows the detailed experimental setup, the measuring devices and the utilized high-speed analysis equipment.

For statistical assurance, the tests were repeated three times with varying cutting parameters (cutting speed $v_{\mathrm{c}}=60 ; 70 ; 80 \mathrm{~m} / \mathrm{min}$, feed $f=0.05 ; 0.06 ; 0.07$ $\mathrm{mm}$, coolant pressure $p=40 ; 80 ; 120$ bar) with a tool diameter of $d=5 \mathrm{~mm}$ and a drilling depth of $1=5 \mathrm{~mm}$. The investigations showed that the most favorable chips could be produced at a cutting speed of $v_{c}=70 \mathrm{~m} / \mathrm{min}$, a feed rate of $f=0.07 \mathrm{~mm}$ and a cooling lubricant pressure of $p=80$ bar $^{[18]}$, so these values were used as input data for the CFD simulation.

\subsection{Experiment results and flow characteristics}

The use of transparent acrylic glass and high-speed microscopy in helical deep drilling provided the possibility to measure and evaluate the coolant flow under real conditions and under the influence of chip formation (Figure 3). The images taken with the Keyence VW9000 high-speed camera could be enlarged by a factor of 50 and the structure sizes could be resolved to $10 \mu \mathrm{m}$ at a maximum image frequency of 4000 fps. The temporally staggered images clearly show that bubble formation occurs with progressive movement of the tool and under the supply of the deep drilling oil and that cavitation is fully formed 
shortly in front of the bore ground. When the tool contacts the workpiece, the bubbles implode and a large number of smaller air bubbles are distributed along the chip and the clamping groove in feed direction. In

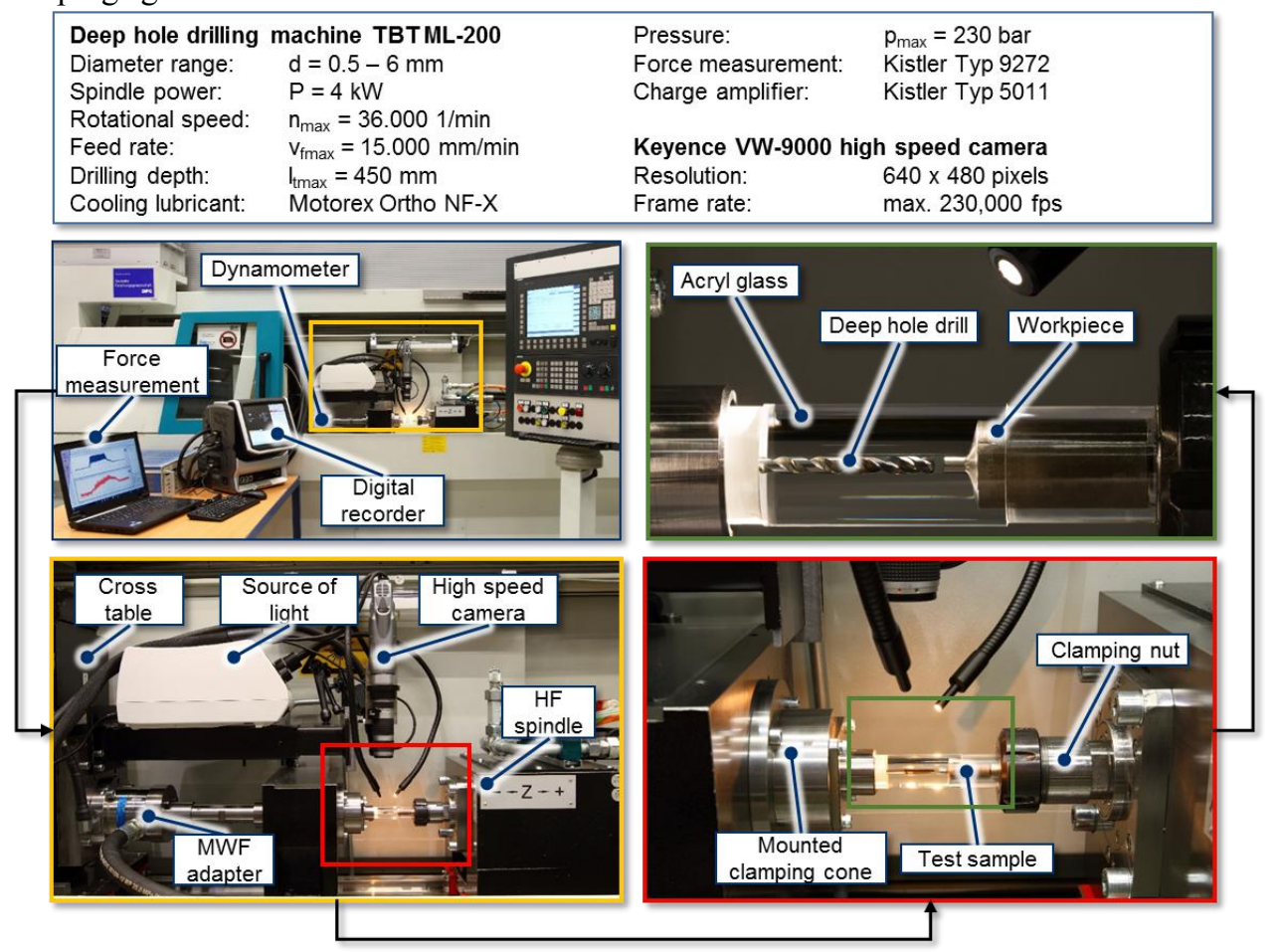

Figure 2. Experimental setup with use of high-speed analysis and measuring equipment

\begin{tabular}{|llll|}
\hline Deep hole drilling process & Drilling depth: & $I=5 \mathrm{~mm}$ \\
Workpiece material: & X2CrNiMo17-12-2 (AISI 316L) & Pressure: & $p=80 \mathrm{bar}$ \\
Tool: & deep hole drill & Cutting speed: & $V_{c}=70 \mathrm{~m} / \mathrm{min}$ \\
Diameter: & $d=5 \mathrm{~mm}$ & Feed: & $f=0.07 \mathrm{~mm}$ \\
\hline
\end{tabular}

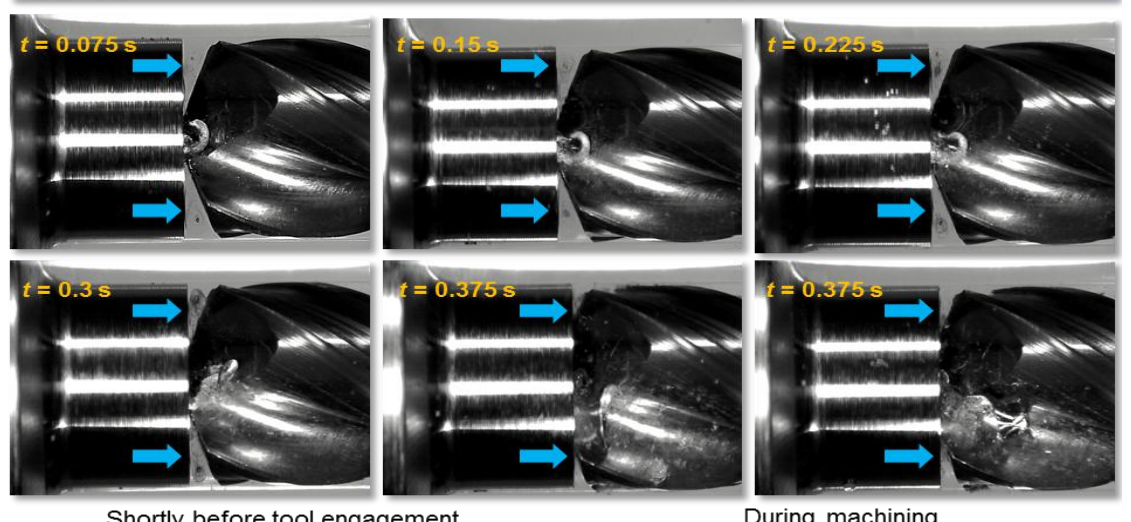

Shortly before tool engagement
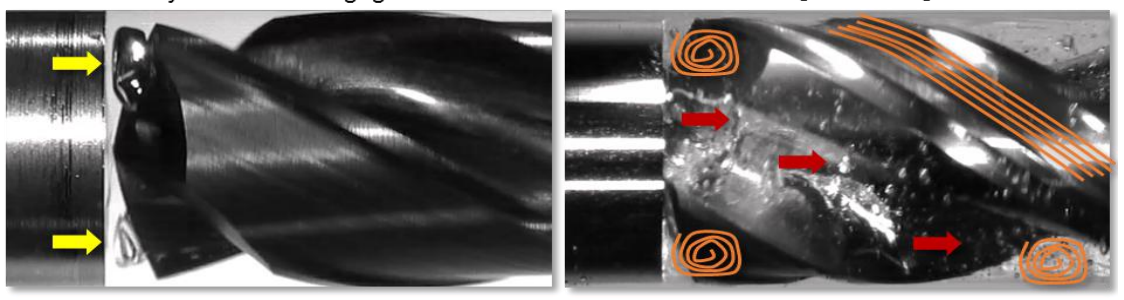

Flow characteristics

$\Rightarrow$ Cavitation formation $\Rightarrow$ Bubble formation in the whole flute $\Rightarrow$ Big cavitation

(Q) Separating vortices Streamline on the land chamfer formation

Figure 3; Experimental analysis of the flow characteristics. 


\section{Mathematical formulation for flow analysis}

For the solution of basic fluid mechanical equations, the Boltzmann equation, which describes the statistical distribution of the individual particles present in the fluid in the physical as well as in the velocity space, can be used. Thereby, the continuum mechanical conservation equations are utilized, which are derived from the Boltzmann equation by a moment formation, to the Navier-Stokes equations, which apply to Newtonian fluids. From the Navier-Stokes equations, further equations such as the Euler equations (friction-free elastic fluids) or the potential equations (rotation-free flow) can be derived by model simplifications. The Navier-Stokes equations are based on the material-independent conservation equations and describe the flow movement of viscous, isotropic liquids. For incompressible fluids, the Navier-Stokes equation corresponds to:

$$
\frac{\partial \mathrm{u}}{\partial \mathrm{t}}+\mathrm{u} \nabla \mathrm{u}=\nabla \overrightarrow{\mathrm{p}}+\mathrm{v} \Delta \mathrm{u}+\overrightarrow{\mathrm{f}} \mid \Delta \mathrm{u}=0
$$

whereby $\vec{p}$ is the quotient of physical pressure and density, $\vec{f}$ is the quotient of volume force and density, $v$ is the quotient of dynamic viscosity and density, $t$ is time and $\mathrm{u}$ is the space coordinate. Since the conservation equations are supplemented by thermal and caloric equations of state and shock relationships, as well as normal and shear stresses, five unknowns remain for the mathematical determination of the flow. These are defined as variable or constant physical or numerical boundary conditions in the CFD software. Due to the flow ranges to be investigated, the mesh grids must be very fine and therefore contain high mesh node numbers, which increases the computing times accordingly. To ensure that the simulation times are acceptable in practice, the Reynolds-averaged Navier-Stokes equations (RANS), such as the RANS $k$ $\omega$-SST turbulence model, are often used, achieving better results than the standard k- $\varepsilon$ turbulence model and the standard $k$ - $\omega$ turbulence model ${ }^{[6,7]}$. Since the choice of a suitable turbulence model is an important aspect of flow analysis ${ }^{[6,19]}$ and computer performance is constantly progressing, this study aims to compare the RANS $k$ - $\omega$-SST turbulence model branch equation turbulence model and the newer high-resolution turbulence model, the Scale-adaptive simulation (SAS) turbulence model, and to evaluate the results with regard to their practical suitability.

\subsection{Turbulence model RANS $\boldsymbol{k}$ - $\boldsymbol{\omega}$-SST}

The turbulence model $k$ - $\omega$-SST, according to Menter $^{[20]}$, is a dual equation vortex viscosity model, which combines the advantages of the standard $k-\varepsilon$ turbulence model and the standard $k$ - $\omega$ turbulence model. Flow areas near walls can be well described with the $k$ - $\omega$ turbulence model and the logarithmic flow (wall distant areas) with the $\mathrm{k}-\varepsilon$ turbulence model. The two equation models are added in the $k-\omega$ formulation and for the $\mathrm{k}$ and $\omega$ equations of the $k$ - $\omega$-SST, the following terms for turbulent kinetic energy are obtained:

$$
\frac{\partial \varrho \mathrm{k}}{\partial \mathrm{t}}+\nabla(\varrho \mathrm{k})=\tau_{\mathrm{ij}} \frac{\partial \mathrm{u}_{\mathrm{i}}}{\partial \mathrm{x}_{\mathrm{j}}}-c_{\mu} \varrho \omega \mathrm{k}+\frac{\partial}{\partial \mathrm{x}_{\mathrm{j}}}\left[\left(\mu+\sigma_{\mathrm{k}} \mu_{\mathrm{t}}\right) \nabla \mathrm{k}\right]
$$

The specific dissipation rate results in:

$$
\begin{gathered}
\frac{\partial \varrho \omega}{\partial \mathrm{t}}++\nabla(\varrho \omega)=\frac{\mathrm{y}}{\mathrm{v}_{\mathrm{t}}} \tau_{\mathrm{ij}} \frac{\partial \mathrm{u}_{\mathrm{i}}}{\partial \mathrm{x}_{\mathrm{j}}}-\beta \varrho \omega^{2}+\nabla\left[\left(\mu \sigma_{\omega} \mu_{\mathrm{t}}\right) \frac{\partial \omega}{\partial \mathrm{x}_{\mathrm{j}}}\right] \\
+2\left(1-\mathrm{F}_{1}\right) \varrho \sigma_{\omega 2} \frac{1}{\omega} \nabla \mathrm{k} \nabla \omega
\end{gathered}
$$

The turbulent viscosity $\mu_{t}$ can be calculated in relation to $k$ and $\omega$ as follows:

$$
\begin{aligned}
& \mu_{\mathrm{t}}=\varrho \frac{\alpha_{1} \mathrm{k}}{\max \left(\alpha_{1} \omega ; \Omega \mathrm{F}_{2}\right)} \\
& \omega=\frac{1}{\partial \mathrm{u}_{\mathrm{i}}} \frac{\varepsilon}{\beta^{*}}, \varepsilon=\mathrm{v} \frac{\partial \mathrm{u}_{\mathrm{i}}}{\partial \mathrm{x}_{\mathrm{k}}} \frac{1}{\partial \mathrm{x}_{\mathrm{k}}}
\end{aligned}
$$

The $F_{2}$ function is a modeling function that takes the distance to the next wall into account. It limits the turbulent viscosity, has values between zero (large wall distances) and one (small wall distances), so that the predominance $\Omega$ only comes into effect in the vicinity of walls. The modelling function $F_{2}$ is calculated with:

$$
\mathrm{F}_{2}=\tanh \left[\max \left(\frac{2 \sqrt{\mathrm{k}}}{c_{\mu} \omega \mathrm{y}}, \frac{500 \mathrm{v}}{\mathrm{y}^{2} \omega}\right)^{2}\right]
$$

The blending function $F_{l}$ activates the $k$ - $\omega$ turbulence model near the wall and the $k-\varepsilon$ turbulence model in the free flow:

$$
\mathrm{F}_{1}=\tanh \left\{\min \left[\max \left(\frac{2 \sqrt{\mathrm{k}}}{c_{\mu} \omega \mathrm{y}} ; \frac{500 \mathrm{v}}{\mathrm{y}^{2} \omega}\right),\left(\frac{4 \varrho \sigma_{\omega 2} \mathrm{k}}{\mathrm{CD}_{\mathrm{k} \omega \mathrm{y}^{2}}}\right)\right]^{4}\right\}
$$

To calculate the inner part of the boundary layer by the $k$ - $\omega$ turbulence model and the outer part and the rest of the flow area by the $k-\varepsilon$ turbulence model, a transfer function using the cross-diffusion term $\mathrm{CD}_{\mathrm{k} \omega}$ is required:

$$
\mathrm{CD}_{\mathrm{k} \omega}=\max \left(\frac{2 \varrho}{\sigma_{\omega 2} \omega} \nabla \mathrm{k} \nabla \omega ; 10^{-20}\right)
$$

The model coefficients $\varnothing$ are calculated using the blending function:

$$
\emptyset=\mathrm{F}_{1} \emptyset_{1}+\left(1-\mathrm{F}_{1}\right) \emptyset_{2}
$$

The values of the model coefficients are listed in Table 1.

Table 1 Turbulence model RANS $k$ - $\omega$ SST 
coefficients

\begin{tabular}{|c|c|c|c|c|c|c|c|c|}
\hline \multirow[b]{2}{*}{$\mathrm{c}_{\mu}$} & \multicolumn{4}{|c|}{$\emptyset_{1}$ (near-wall range) } & \multicolumn{4}{|c|}{$\emptyset_{2}$ (no-wall range) } \\
\hline & $\alpha_{1}$ & $\beta_{1}$ & $\sigma_{\mathrm{k} 1}$ & $\sigma_{\omega 1}$ & $\alpha_{2}$ & $\beta_{2}$ & $\sigma_{\mathrm{k} 2}$ & $\sigma_{\omega 2}$ \\
\hline 09 & 0.31 & 0.075 & 0.85 & 0.5 & 0.44 & 0.082 & & 0.856 \\
\hline
\end{tabular}

\subsection{Turbulence model RANS hybrid SAS-SST}

The hybrid turbulence model SAS introduced by Menter et al. is based on the formulation of the RANS- $k$ $\omega$-SST model and is an extended Unsteady Reynolds Averaged Navier-Stokes (U-RANS) model ${ }^{[21]}$. The hybrid SAS model allows a finer resolution of the turbulent flow by introducing the physical, turbulent linear scale according to Karman. In the statistical turbulence models, detached flows can only be depicted insufficiently, since the temperature and flow fluctuations are strongly dampened by the vortex viscosity models. In the hybrid SAS, the boundary layer near the wall and the vortices with a diameter below the grid resolution are represented with the U-RANS model and the currents far from the wall are described by an LES model. The hybrid SAS turbulence model is based on the standard $\mathrm{k}-\varepsilon$ and $k$ - $\omega$ turbulence model, but has been modified as follows compared to the RANS $k$ $\omega$-SST turbulence model:

$$
\begin{aligned}
\frac{\partial \varrho \mathrm{k}}{\partial \mathrm{t}}+\nabla(\varrho \vec{u} \mathrm{k})=\mu_{\mathrm{t}} S^{2} & -\varrho c_{\mu} \mathrm{k} \omega+\nabla\left[\left(\mu+\sigma_{\mathrm{k}} \mu_{\mathrm{t}}\right) \nabla \mathrm{k}\right] \\
\frac{\partial \varrho \omega}{\partial \mathrm{t}}++\nabla(\varrho \vec{u} \omega)= & \alpha \frac{\mathrm{k}}{\omega} \mu_{\mathrm{t}} S^{2}-\varrho \beta \omega^{2}+\mathrm{Q}_{\mathrm{SAS}} \\
& +\nabla\left[\left(\mu+\sigma_{\omega} \mu_{\mathrm{t}}\right) \nabla \omega\right] \\
& +\left(1-\mathrm{F}_{1}\right) \frac{2 \varrho \sigma_{\omega 2}}{\omega} \nabla \mathrm{k} \nabla \omega
\end{aligned}
$$

This causes the values of $\omega$ to be greatly increased if discontinuity of the calculated velocity gradients occurs over two adjacent arithmetic cells. This reduces the vortex viscosity compared to the SST turbulence model, i.e. the diffusion term and thus the damping of the velocity gradients in the impulse equation are weaker, so that vortices can also be simulated in a few arithmetic cells. The source term $Q_{S A S}$ is based on the Karman-Length-Scale $\mathrm{L}_{\mathrm{vK}}$ according to the definition developed by Kármán ${ }^{[22]}$ :

$$
\mathrm{L}_{\mathrm{VK}}=\max \left(\frac{\kappa \mathrm{S}}{\left|\nabla^{2} \mathrm{U}_{\mathrm{j}}\right|}, \mathrm{C}_{\mathrm{S}} \sqrt{\frac{\kappa \zeta_{2}}{\frac{\beta}{c_{\mu}}-\alpha}} \sqrt[3]{\mathrm{V}_{\mathrm{CV}}}\right)
$$

With the first term, the length of the mixture path is formulated in three dimensions and with the second term, it is limited by the fluid volume size. This Karman length scale is based on the definition of the mixing path length in the boundary layer and is determined by $k$ and $\omega$ in relation to the length $\mathrm{L}$ of the character. In contrast to the RANS $k$ - $\omega$-SST turbulence model, which takes into account the turbulence effects in the shear layers but not the effects caused by vortices ${ }^{[23]}$, the hybrid SAS turbulence model can be used to analyze not only the apparent viscosity, but also the velocity gradients that occur in the second order. Thus, effects resulting from the shear layers as well as those of large turbulence vortices are taken into account. For the source term $\mathrm{Q}_{\mathrm{SAS}}$, this results in:

$$
\mathrm{Q}_{\mathrm{SAS}}=\max \left[\varrho \zeta_{2} \kappa S^{2}\left(\frac{\mathrm{L}}{\mathrm{L}_{\mathrm{VK}}}\right)^{2}-\frac{\mathrm{c} 2 \mathrm{k}}{\sigma_{\Phi}} \max \left(\frac{|\nabla \omega|^{2}}{\omega^{2}}, \frac{|\nabla \mathrm{k}|^{2}}{\mathrm{k}^{2}}\right), 0 \frac{\mathrm{kg}}{\mathrm{m}^{3} \mathrm{~s}^{2}}\right]
$$

In equations 11 and 12 , the stress tensor is defined as S:

$$
\mathrm{S}=\sqrt{2 \mathrm{~S}_{\mathrm{ij}} \mathrm{S}_{\mathrm{ji}}}
$$

The values for the constants are listed in Table 2:

\begin{tabular}{cl} 
Constant & Value \\
\hline$c_{\mu}$ & 0.09 \\
\hline $\mathrm{c}$ & 2 \\
\hline $\mathrm{c}_{\mathrm{s}}$ & 0.215 \\
\hline$\alpha$ & 0.44 \\
\hline$\beta_{1}$ & 0.075 \\
\hline$\beta_{2}$ & 0.0828 \\
\hline$\zeta_{2}$ & 3.51 \\
\hline$\kappa$ & 0.41 \\
\hline$\sigma_{\omega 2}$ & 0.856 \\
\hline$\sigma_{\Phi}$ & $2 / 3$
\end{tabular}

Table 2. Model constant for the RANS hybrid SAS-SST turbulence model

So that the apparent viscosity, as is the case with the classic hybrid SAS model ${ }^{[24]}$, is not too large and the flow fluctuations are calculated as too small ${ }^{[25]}$, Menter proposed a solution ${ }^{[26]}$. To stimulate weak instabilities by artificial stochastic velocity fluctuations $u_{f, i}$, the source term $F_{i m p, i}$ was added to the pulse equation:

$$
\mathrm{F}_{\mathrm{imp}, \mathrm{i}}=\frac{\mathrm{eu}_{\mathrm{f}, \mathrm{i}}}{\nabla \mathrm{t}}
$$

To ensure consistency, the cavity term $F_{k}$ is introduced into the balance of kinetic energy of turbulence ${ }^{[24]}$.

$$
\mathrm{F}_{\mathrm{k}}=-0.5 \frac{\mathrm{eu}_{\mathrm{f}, \mathrm{i}}^{2}}{\nabla \mathrm{t}}
$$

The velocity fluctuations are calculated according to the approach of the fluctuations by Batten et al. ${ }^{[27]}$ by determining them via the turbulent kinetic energy and the dissipation rate per kinetic energy: 


$$
\begin{aligned}
& \mathrm{u}_{\mathrm{f}, \mathrm{i}}=\sqrt{\frac{2}{3} \mathrm{k}} \sqrt{\frac{2}{\mathrm{~N}}} \sum_{\mathrm{n}=1}^{\mathrm{N}}\left[\epsilon_{\mathrm{i}, \mathrm{j}, \mathrm{k}} \eta_{\mathrm{j}}^{\mathrm{n}} \mathrm{d}_{\mathrm{k}}^{\mathrm{n}} \cos \left(\arg ^{\mathrm{n}}\right)\right. \\
& \left.+\epsilon_{\mathrm{i}, \mathrm{j}, \mathrm{k}} \xi_{\mathrm{j}}^{\mathrm{n}} \mathrm{d}_{\mathrm{k}}^{\mathrm{n}} \sin \left(\arg ^{\mathrm{n}}\right)\right] \\
& \arg ^{n}=2 \pi\left(\frac{d_{i}^{n} x_{i}}{L_{t}}+\frac{v_{i}^{n} t}{t_{t}}\right)
\end{aligned}
$$

whereby the variables $\eta_{i}^{n}, \xi_{i}^{n}, d_{i}^{n}$ and $v_{i}^{n}$ are normally distributed random variables that generate stochastic turbulence fluctuations and are determined via the normal distribution $\mathcal{N}(\varphi ; \psi)$ with the expected value $\varphi$ and the standard deviation $\psi$, while $\epsilon_{i, j, k}$ is the Levi-Civita symbol:

$$
\begin{gathered}
\mathrm{L}_{\mathrm{t}}=0.5 \frac{\sqrt{\mathrm{k}}}{\mathrm{c}_{\mu} \omega} \\
\mathrm{t}_{\mathrm{t}}=\frac{\mathrm{L}_{\mathrm{t}}}{\sqrt{\mathrm{k}}} \\
\frac{\mathrm{L}_{\mathrm{t}}}{\left|\mathrm{d}^{\mathrm{n}}\right|} \geq 2 \nabla \mathrm{x} ; \frac{\mathrm{t}_{\mathrm{t}}}{\mathrm{v}_{\mathrm{i}}^{\mathrm{n}}} \geq 2 \nabla \mathrm{x}
\end{gathered}
$$

$L_{t}$ and the characteristic time $t_{t}$ are used to determine the spatial and temporal course of the fluctuation values, which are limited by ${ }^{[24]}$ :

$$
\begin{aligned}
\eta_{\mathrm{j}}^{\mathrm{n}}=\mathcal{N}(0 ; 1) ; \xi_{\mathrm{j}}^{\mathrm{n}}= & \mathcal{N}(0 ; 1) ; \mathrm{d}_{\mathrm{i}}^{\mathrm{n}}=\mathrm{d}_{\mathrm{i}}^{\mathrm{n}} \mathcal{N}(0 ; 0.5) ; \mathrm{v}_{\mathrm{i}}^{\mathrm{n}} \\
& =\mathcal{N}(1 ; 1)
\end{aligned}
$$

\section{CFD modelling and simulation setup}

The real helical tool was digitized using an Infinitefocus G5 scanner from Alicona, to subsequently create a realistic fluid model. In order to analyze the tribological load in the contact zone between tool tip and bore ground in detail, the digitized data was imported into the software Geomagic, so that a reverse engineering of the surface profile could carried out and a kinematic imprint of the contact zone could be created with the CAD software SolidWorks CAD ${ }^{[28]}$. Out of the CAD model, consisting of tool, bore ground (workpiece) and bore wall, a negative model was generated, which corresponds to the fluid domain, and imported into the software ANSYS for further processing. Due to the required high mesh grid quality with a corresponding large number of elements and due to the usage of modern and complex turbulence models, an adequately high computing power was necessary for the CFD calculation. Therefore, a high performance computing system (HPC) with 64 processors was used.

In order to define the simulation boundary conditions, it is necessary to differentiate the interfaces between the solid and fluid bodies. Therefore, the two internal cooling channels of the helical deep hole drill were defined as an inlet and the flutes as an outlet. A special feature of this study compared to conventional CFD calculations, which use water as an incompressible

\begin{tabular}{|c|c|c|}
\hline $\begin{array}{l}\text { Calculation type: } \\
\text { transient }\end{array}$ & time & $t_{t}=10 \mathrm{~s}$ \\
\hline Simulation time steps & time & $\mathrm{t}_{\mathrm{s}}=0.0135 \mathrm{~s}$ \\
\hline Fluid & $\begin{array}{l}\text { metal working } \\
\text { flow oil }\end{array}$ & - \\
\hline $\begin{array}{l}\text { Metal working flow } \\
\text { oil }\end{array}$ & temperature & $\mathrm{T}=308.15 \mathrm{~K}$ \\
\hline \multirow[t]{2}{*}{ Inlet } & pressure & $p=80$ bar \\
\hline & mass flow & $\dot{\mathrm{m}}=0.6 \mathrm{~kg} \cdot \mathrm{s}^{-1}$ \\
\hline $\begin{array}{l}\text { Outlet: ambient } \\
\text { pressure }\end{array}$ & pressure & $p_{a m b}=1 \mathrm{bar}$ \\
\hline $\begin{array}{l}\text { Interface 1: } \\
\text { workpiece/fluid }\end{array}$ & friction & $0.01 \mathrm{~mm}$ \\
\hline Interface 2: tool/fluid & friction & smooth \\
\hline Interface 1, 2 & rotational speed & $\mathrm{n}=45561 / \mathrm{min}$ \\
\hline Fluid model & $\begin{array}{l}\text { number of } \\
\text { elements }\end{array}$ & ca. 2.5 Million \\
\hline $\begin{array}{l}\text { Inflation-layer: first } \\
\text { layer }\end{array}$ & length & $2.5 \mathrm{e}-04 \mathrm{~mm}$ \\
\hline $\begin{array}{l}\text { Inflation-layer: } \\
\text { growth rate }\end{array}$ & factor & 1.2 \\
\hline Turbulence model & type & RANS $k-\omega$-SST \\
\hline $\begin{array}{l}\text { Modified turbulence } \\
\text { model }\end{array}$ & type & $\begin{array}{l}\text { RANS hybrid } \\
\text { SAS }\end{array}$ \\
\hline
\end{tabular}
fluid, is the modeling of deep drilling oil, as it is also used in the real process. The numerical calculation includes the tool rotation and the according movement of the deep drilling oil. The entire simulation boundary conditions for the flow simulation are listed in Table 3.

Deep hole drill with internal coolant channels

Table 3. Simulation boundary conditions

The process of CFD mesh generation is an important factor for the accuracy of the results and for the benchmark investigation, which is unfortunately often still underestimated in machining technology. The likely reason for this is that in contrast to CFD, the Finite Element Method (FEM) is a long established instrument and therefore its handling is more familiar. CFD not only differs in modeling, where the fluid model represents the negative impression of tool and workpiece and the contact interfaces must be clearly defined with all their boundary conditions, but in particular also in the way in which the models are meshed. In contrast to FE analysis, where more elements have to be meshed in areas where the solution variables have high spatial gradients, the physical phenomenon of the pressure-speed coupling in the mesh is precisely represented in the $\mathrm{CFD}$, in order to ensure the continuity 
of the fluid mass over the entire solution domain. The cross-linking of the prism layer (inflation layer, first layer) takes place at the boundary layers and must be of high quality in order to ensure that the flow field is reproduced realistically. The resolution of the calculation grids, i.e. the meshing strategy must be adapted to the geometry and physical properties of the fluid model and often results in a total number of elements in the million range. The choice of the inflation layer is based on experience and is initially chosen accordingly. Since high speed gradients are present near the wall, the thickness of the boundary layer generally has to be smaller with an increasing Reynolds number. To check whether the boundary layers have been selected sufficiently fine, it is therefore necessary to perform an analytical calculation after the simulation, to determine the dimensionless wall distance $\left(\mathrm{y}^{+}\right.$value). The density of the used deep drilling oil $\rho$, the dynamic viscosity $\mathrm{v}$, the wall shear stress $\tau_{\omega}$ and the wall distance $\mathcal{Y} P$, the wall shear stress velocity $u_{\tau}$, the vectorial velocity $\vec{u}$ and the nominated velocity $u^{+}$must be taken into account:

$$
\begin{gathered}
\mathrm{u}^{+}=\frac{|\overrightarrow{\mathrm{u}}|}{\mathrm{u}_{\tau}} \\
\mathrm{y}^{+}=\frac{\rho \mathrm{u}_{\tau} \mathcal{Y} P}{\mathrm{v}} \\
\mathrm{u}_{\tau}=\sqrt{\frac{\tau_{\omega}}{\rho}}
\end{gathered}
$$

The $\mathrm{y}^{+}$value of a turbulent boundary layer can be summarized as follows ${ }^{[29]}$ :

- $\quad$ Viscous undercoat $\left(\mathrm{y}^{+}<5\right)$

- $\quad$ Buffer layer or blending region $\left(5<\mathrm{y}^{+}<30\right)$

- $\quad$ Fully turbulent or log-law region $\left(\mathrm{y}^{+}>30\right.$ to 60$)$

Figure 4 shows the cross-linking of the fluid model with the locally very fine cross-linking areas (a) and the areas of boundary layer cross-linking (b). In these areas it is no longer possible to work with automatic meshing methods, due to the very small dimensions and the complex three-dimensional tool design, i.e. these mesh regions must be generated manually with the ICEM-CFD mesh generator in order to create an optimal grid topology. The boundary layer requires at least 3 layers, increasing in thickness starting from the 1st layer, with a growth rate of 1.2 .
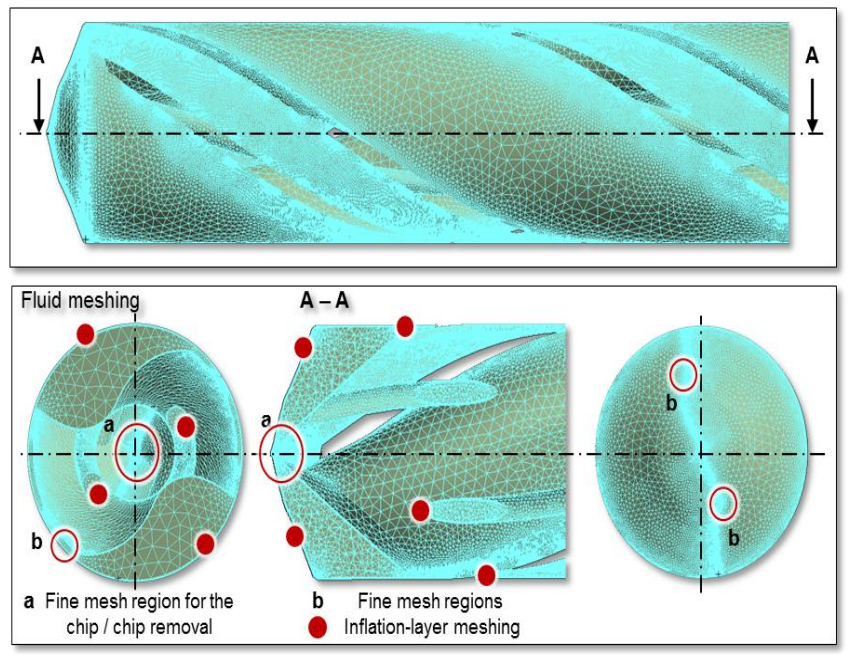

Figure 4; Meshing of fluid model.

\section{Simulation results and comparison of turbulence models}

The simulation results of RANS $k$ - $\omega$-SST turbulence model were compared to the experimentally optically recorded results in equal time intervals (Figure 5). The numerically calculated flow velocities were displayed in the form of vector, streamline and the $\mathrm{Q}$ criterion. Thus, the direction of the flow gradients, the flow course and the distribution of the fluid volume in the feed direction could be analyzed and the vortices formed therein and their velocity could be identified and visualized. Since different vortex definitions still exist today, many researchers have dealt with the description ${ }^{[30-32]}$. In CFD, vortices are defined as a flow showing a circular, rotating course and dissipating energy. These vortices form and interact with each other, while their behavior is irregular and chaotic according to the initial and boundary conditions. The stochastic and three-dimensional character shows that the formation of the vortices in a fully developed turbulence is strongly dependent on time ${ }^{[33]}$. Vortices can be analyzed with some methods, but only the $\mathrm{Q}$ criterion, predictor- and the $\lambda_{2}$-method are suitable for analysis in transient flows, since the vortices often move in the middle flow field. The flow field is divided into elliptical and hyperbolic areas. Since the $\mathrm{Q}$ criterion assumes that the rotational gradients vary considerably faster than the velocity gradients, the corresponding areas are either compressed or stretched. Kolár gives an overview of the popular vortex-identification methods ${ }^{[34]}$.

The numerical results show that the highest flow 
velocity of $v_{s}=110 \mathrm{~m} / \mathrm{s}$ occurs directly at the outlet of the internal cooling channels. The velocity vectors indicate that the deep drilling oil is applied to the workpiece at an average flow velocity of $\mathrm{v}_{\mathrm{s}}=55 \mathrm{~m} / \mathrm{s}$ but the fluid is deflected away from the tool cutting edges by the tool's rotary movement. The flow curve shows that the speed of the fluid at the cutting edge and at the first chip formation decreases strongly and even drops to 0 in partial areas and at the flutes. The analysis of the fluid volume also shows that only immediately after the deep drilling oil evicts, a strong flow speed occurs, but that the cutting edges of the tool are not at all sufficiently cooled.

Chip removal also seems to be adversely affected.

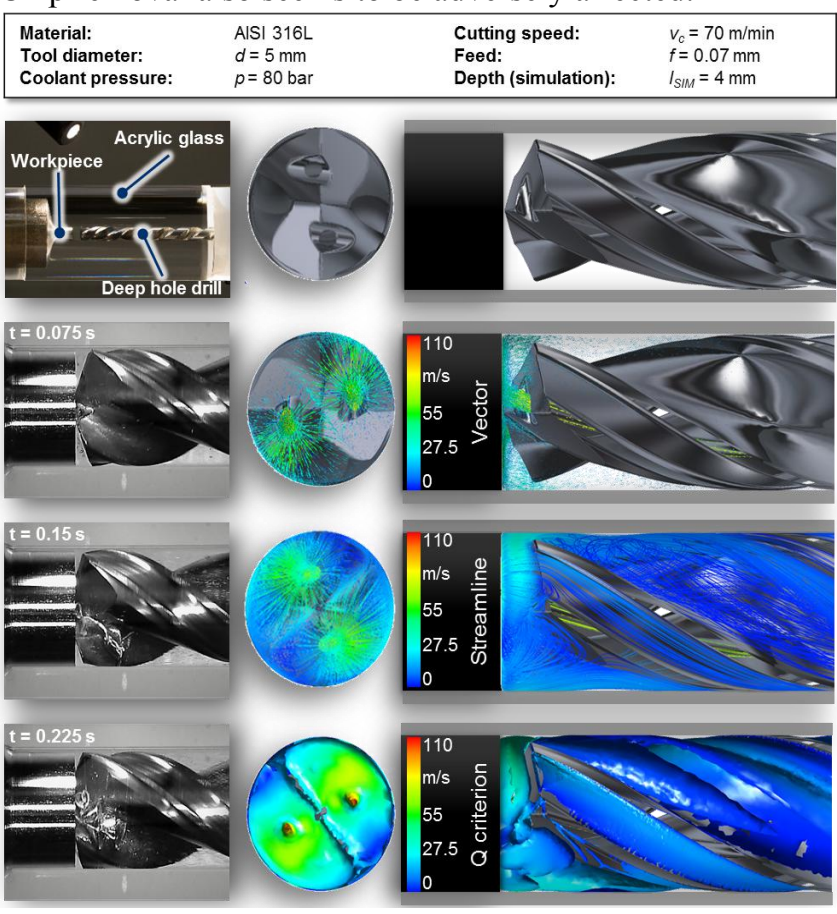

Figure 5; Comparison of the simulation results of the $k$ - $\omega$ -SST model to the experimental results.

The representation of flow distribution and vortex formation via $\mathrm{Q}$ criterion in Figure 6 show that in helical deep drilling the deep drilling oil hardly reaches the tool cutting edges. When comparing numerical and experimental results, the RANS hybrid SAS-SST turbulence model shows a much better resolution of flow and vortices than the RANS $k$ - $\omega$-SST turbulence model. The hybrid SAS-SST model thus represents the real fluid behavior better than the RANS $k$ - $\omega$-SST turbulence model. It can be observed that the drill tip is surrounded by a medium high flow velocity as it begins to cut the workpiece and a relatively large vortex formation occurs in the flute. However, because the flow velocity drops very rapidly in large areas, there is hardly any movement of the fluid.

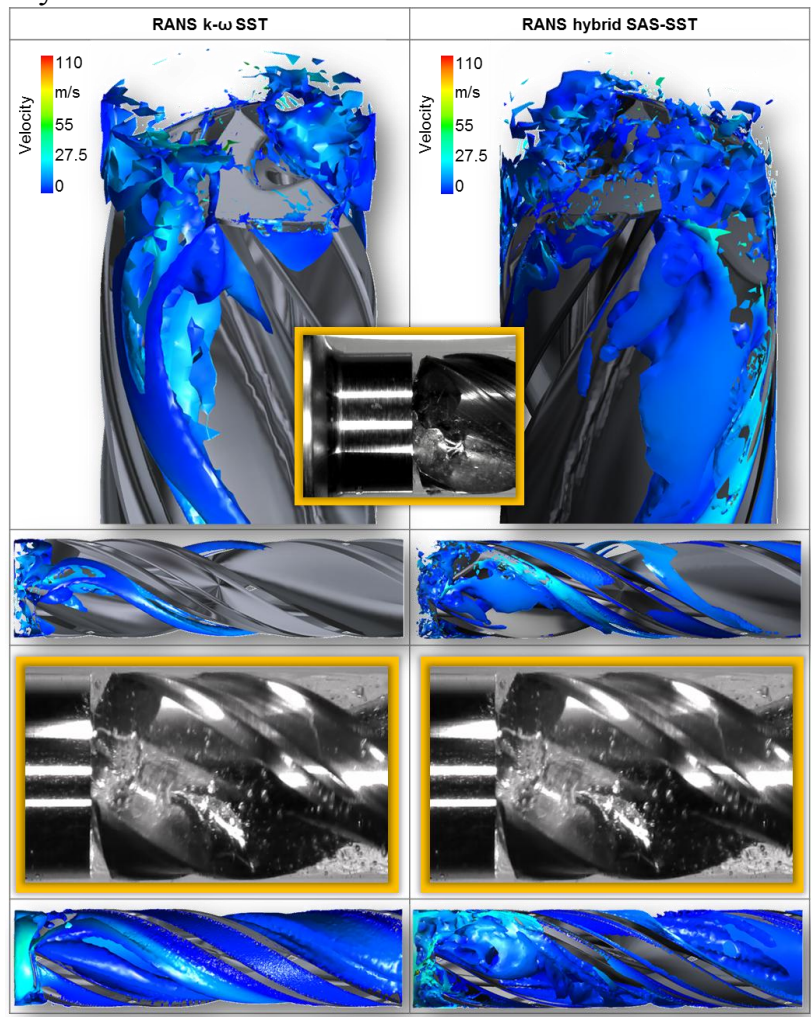

Figure 6; Comparison of the simulation results of the RANS- $k$ - $\omega$-SST turbulence model and RANS hybrid SAS-SST turbulence model using the Q criterion.

The streamlines are much more pronounced in the RANS hybrid SAS-SST turbulence model and thus the flow curve and the kinetic energy are more comprehensible than in the RANS $k$ - $\omega$-SST turbulence model (Figure 7). The fluid velocity in the RANS hybrid SAS-SST turbulence model is higher at both the exit surfaces of the internal cooling channels and at the outer area of the clamping groove in comparison to the RANS $k$ - $\omega$-SST turbulence model. As can be seen from the experimental illustration, the formed chip bulges from above towards the inside of the flute and is only forced away by the further penetration of the helical deep drill. The kinetic energy used to set the fluid into motion is very low and also subject to the inertia of the deep drilling oil. Only at the precise moment when the deep drilling oil is ejected from the internal cooling channels at high pressure and speed, the fluid gains kinetic energy. As the pressure increases downstream in the feed direction and friction between tool, workpiece and chip increases, the flow loses kinetic energy. The deep drilling oil is therefore forced away and led out into the free flow. 
The drill tip and the chip dissolve turbulences and carry the flow out into the vortex-free space, thus transporting the energy away from the tool. The cavitation observed during the experimental investigation can be explained in this context. Since the fluid exits the channels at a high speed in the beginning, when the tool tip engages the workpiece surface, there is still a low static pressure in the deep drilling oil. With increasing penetration of the helical drill into the workpiece, the deep drilling oil is pressed away from the cutting edges. The speed at the cutting edges drops almost rapidly to 0 , whereby the heat generated at the tool and chip during machining increases, as it cannot be dissipated and so the static pressure of the deep drilling oil inevitably drops below its evaporation pressure and cavitation bubbles form. During further machining work, the drill tip comes into contact with the fluid reflected from the workpiece, causing the static pressure of the deep drilling oil to rise again, so that the cavitation bubbles to implode abruptly. This implosion is to be assumed to take place in the lower right picture in Figure 7 in the upper area, where the turbulent energy rises to $\mathrm{v}=172.1 \mathrm{~m}^{2} / \mathrm{s}^{2}$ (see Figure 3).

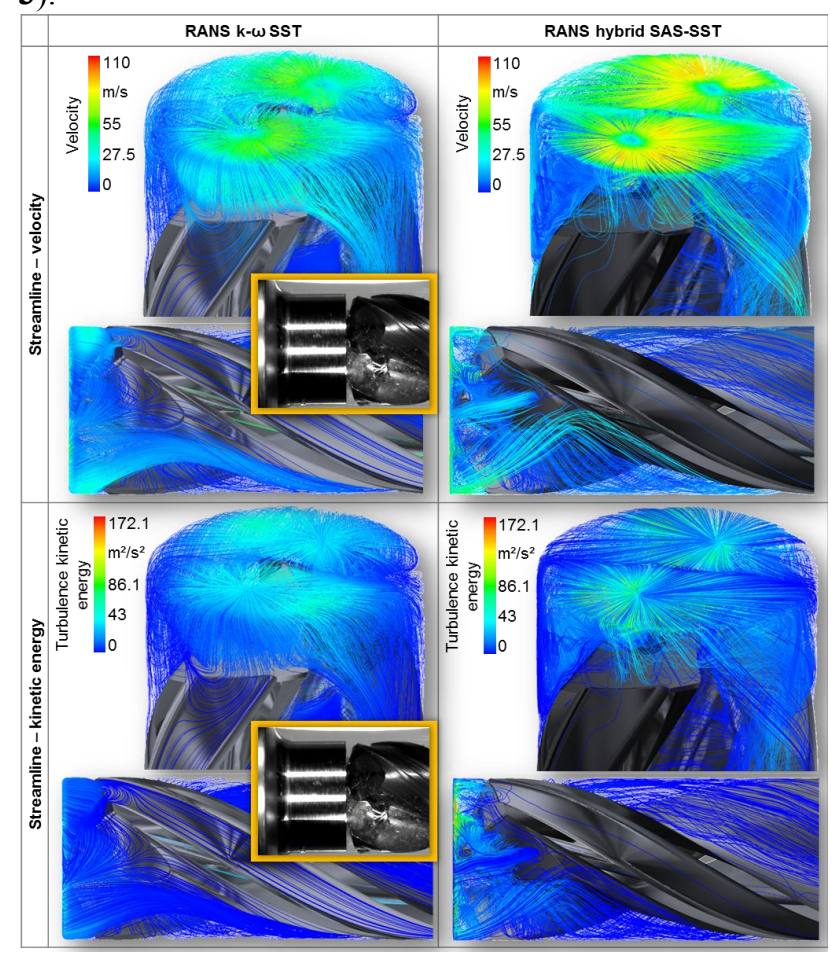

Figure 7; Comparison of the simulation results of the RANS $k$ - $\omega$-SST turbulence model and RANS hybrid SAS-SST turbulence model using flow lines.

Figure 8 shows the contour of the flow velocity and the kinetic energy with different distances of the helical deep hole drill from the workpiece surface. The RANS hybrid SAS-SST turbulence model results in more precise contours than the RANS $k$ - $\omega$-SST turbulence model. The aspects described above can also be observed here. Flow velocity is greatly slowed down immediately after discharge and the cutting edges are only slightly surrounded, if at all, by the deep drilling oil.

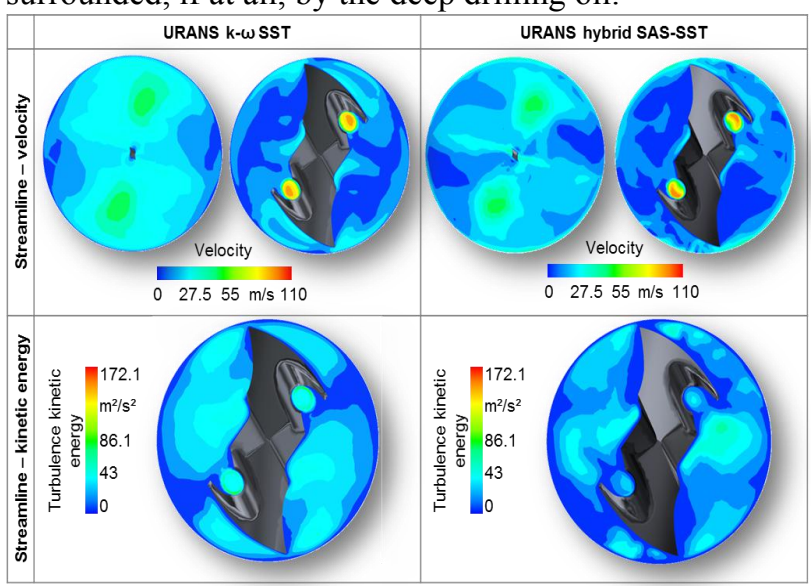

Figure 8; Comparison of the simulation results of the RANS $k$ - $\omega$-SST turbulence model and RANS hybrid SAS-SST turbulence model using the flow contour.

\section{Conclusion}

In this paper, the behavior of deep drilling oil during helical deep drilling was investigated experimentally and simulatively. A newly developed high-speed chip formation analysis method was used in an experimental test setup, so that the flow course during helical deep drilling could be observed using transparent acrylic glass samples. The images recorded with a high-speed camera showed the formation of cavitation bubbles. The results of the RANS $k$ - $\omega$-SST turbulence model, the RANS hybrid SAS-SST turbulence model and the experiment were compared for numerical imaging. The RANS hybrid SAS-SST turbulence model showed a clearly more precise resolution of the flow, so that the behavior of the simulated deep drilling oil could be analyzed in detail. Both the experimental and the simulative results show that the cutting edges are insufficiently supplied with coolant, since the flow velocity almost drops to 0 . The deep drilling oil movement at the chip flute is almost entirely generated by the tool rotation, which could have a negative influence on chip removal. Based on the 
results, it could be concluded that the heat generated between the tool, workpiece and chip cannot be dissipated well due to the low flow velocity. In future investigations, the stochastic chip formation and the thermo-mechanical loads will also be taken into account in fluid modelling, so that the entire process can be investigated. It is clear that there is great research potential, especially in the area of tool optimization.

\section{Acknowledgment}

The authors gratefully acknowledge funding from the German Research Foundation (DFG) for the research project (BI 498/80).

\section{Reference}

1. Abele E; Ellermeier A; Hohenstein J; Tschannerl M: Tool length influence on wear behaviour of twisted carbide drills. Production Engineering, 1 (2007) 1, pp. 51-56

2. Biermann D; Iovkov I; Blum H; Rademacher A, et al.: Thermal Aspects in Deep Hole Drilling of Aluminium Cast Alloy Using Twist Drills and MQL. Procedia CIRP, 3 (2012), pp. 245-250, https://doi.org/ 10.1016/j.procir.2012.07.043

3. Uhlmann E; Richarz S: Twisted deep hole drilling tools for hard machining. Journal of Manufacturing Processes, 24 (2016), pp. 225-230, https://doi.org/10.1016/j.jmapro.2016.09.013

4. Eichler R: Prozeßsicherheit beim Einlippenbohren mit kleinsten Durchmessern. Dissertation Universität Stuttgart, 1996, ISBN 0943-3821

5. Fallenstein F; Aurich JC.: CFD based Investigation on Internal Cooling of Twist Drills. Procedia CIRP, 14 (2014), pp. 293-298, https://doi.org/10.1016/j.procir.2014.03.112

6. Beer N; Oezkaya E; Biermann D: Drilling of Inconel 718 with geometry-modified twist drills. Procedia CIRP, 9 (2014), pp. 49-55, https://doi.org/10.1016/j.procir.2014.07.124

7. Oezkaya E; Beer N; Biermann D: Experimental studies and CFD simulation of the internal cooling conditions when drilling Inconel 718. International Journal of Machine Tools and Manufacture, 108 (2016), pp. 52-65, https://doi.org/10.1016/j.ijmachtools.2016.06.003

8. Biermann D; Oezkaya E: CFD simulation for internal coolant channel design of tapping tools to reduce tool wear. CIRP Annals, 66 (2017) 1, pp. 109-112, https://doi.org/10.1016/j.cirp.2017.04.024

9. Schnabel D; Özkaya E; Biermann D; Eberhard P Modeling the motion of the cooling lubricant in drilling processesusing the finite volume and the smoothed particle hydrodynamics methods. Computer Methods in Applied Mechanics and Engineering, 329 (2017), pp. 369-395, https://doi.org/10.1016/j.cma.2017.09.015
10. Oezkaya E; Biermann D: Decreasing Drill Damage. ANSYS ADVANTAGE MAGAZINE, XI (2017) 1, pp. $24-27$

11. REXTROTH BOSCH GROUP [Accessed 12 May 2018]. URL: https://www.boschrexroth.com

12. Supertechperformance [Accessed 12 May 2018]. URL: https://www.supertechperformance.com/

13. DEPUY SYNTHES DEUTSCHLAND [Accessed 12 May 2018]. URL:

https://emea.depuysynthes.com

14. NORMED [Accessed 13 May 2018]. URL: http://www.normed-online.com/

15. HIMPE [Accessed 13 May 2018]. URL: http://www.himpe.de/

16. ABB [Accessed 13 May 2018]. URL: http://new.abb.com/de

17. Biermann D.; Kirschner M.; Eberhardt D: A novel method for chip formation analyses in deep hole drilling with small diameters. Production Engineering, 8 (2014) 4, pp. 491-497, https://doi.org/10.1007/s11740-014-0566-7

18. Oezkaya E; Michel S; Biermann D: Experimental studies and FEM simulation of helical-shaped deep hole twist drills. Production Engineering, 12 (2018) 1, pp. 11-23, https://doi.org/10.1007/s11740-017-0779-7

19. Versteeg HK; Malalasekera W: An introduction to computational fluid dynamics. Pearson Education Ltd., Harlow, England, 2007, ISBN 978-0131274983

20. Menter FR; Kuntz M; Langtry, R.: Ten Years of Industrial Experience with the SST Turbulence Model. Turbulence, Heat and Mass Transfer 4 (2003), pp.625-632

21. Menter FR: A scale-adaptive simulation model using two-equation models. AIAA paper 2003-0767, Reno, NV (2003)

22. Kármán T: Mechanische Ähnlichkeit und Turbulenz. 3. Internationaler Kongress für Technische Mechanik , pp. 85-93

23. Menter FR; Egorov Y: The Scale-Adaptive Simulation Method for Unsteady Turbulent Flow Predictions. Part 1: Theory and Model Description. Flow, Turbulence and Combustion, 85 (2010) 1, pp. 113-138

24. Domnick CB: Untersuchung des strömungs- und strukturdynamischen Verhaltens von Dampfturbineneinlassventilen im Teillastbetrieb. Dissertation, Universität Duisburg - Essen, 2016

25. David Lee Davidson: The Role of Computational Fluid Dynamics in Process Industries. The Bridge, 32 (2002) 4, pp. 9-14

26. Menter FR: Turbulence Modeling for Engineering Flows. ANSYS, A Technical Paper (2011), pp. 1-25

27. Batten P; Goldberg U; Chakravarthy S: Interfacing Statistical Turbulence Closures with Large-Eddy Simulation. AIAA Journal, 42 (2004) 3, pp. 485-492, https://doi.org/10.2514/1.3496

28. Oezkaya E; Biermann D: A new reverse 
engineering method to combine FEM and CFD simulation three-dimensional insight into the chipping zone during the drilling of Inconel 718 with internal cooling. Machining Science and Technology, 51 (2018), S. 1-18, DOI:

10.1080/10910344.2017.1415933

29. Salim MS; Cheah SC: Wall y+ Strategy for Dealing with Wall-bounded Turbulent Flows. Proceedings of the International MultiConference of Engineers and Computer Scientists, Vol II IMECS, March 18 20, 2009, Hong Kong

30. Jeong J; Hussain F: On the identification of a vortex. Journal of Fluid Mechanics, 285 (1995), pp. 69-94, https://doi.org/10.1017/S0022112095000462

31. Cucitore R; Quadrio M; Baron A: On the effectiveness and limitations of local criteria for the identification of a vortex. European Journal of Mechanics - B/Fluids, 18 (1999) 2, pp. 261-282, https://doi.org/10.1016/S0997-7546(99)80026-0

32. Wu J-Z.; Ma H-Y; Zhou M-D: Vorticity and Vortex Dynamics. Springer-Verlag Berlin Heidelberg, Berlin, Heidelberg, 2006, ISBN 978-3-54029-027-8

33. Oezkaya E: FEM-basiertes Softwaresystem für die effiziente 3D-Gewindebohrsimulation und Werkzeugoptimierung mittels CFD-Simulation, Vulkan Verlag, 2016, ISBN 978-3-8027-8793-5

34. Koláŕ V: Vortex identification. International Journal of Heat and Fluid Flow, 28 (2007) 4, pp. 638-652, https://doi.org/10.1016/j.ijheatfluidflow.2007.03.00 4 